\title{
COMPARATIVE EVALUATION OF PLATELET AUGMENTATION ACTIVITY OF CARICA PAPAYA LEAF JUICE AND HYDROCORTISONE IN THROMBOCYTOPENIC RATS
}

\author{
TANSENA AKHTER ${ }^{1}$, MD. ISMAIL KHAN ${ }^{2}$, ELIZA OMAR EVA ${ }^{3}$ \\ ${ }^{1}$ Assistant Professor, Department of Pharmacology, Tairunnessa Memorial Medical College, Gazipur, Bangladesh. \\ ${ }^{2}$ Professor and Head, Department of Pharmacology, Principal, Dhaka Medical College, Dhaka, Bangladesh. \\ ${ }^{3}$ Department of Pharmacology, Dhaka Medical College, Dhaka, Bangladesh.
}

\begin{abstract}
Aim

The study aims at determining the possible effects of Carica papaya leaf juice and hydrocortisone in increasing the platelet count in thrombocytopenia similar to dengue fever.

Methodology

The study was carried out on 24 Long Evans Norwegian strain healthy rats to investigate the comparative platelet increasing effect of Carica papaya leaf juice and hydrocortisone in experimentally induced thrombocytopenic rats. Thrombocytopenia was induced by 3 doses of cyclophosphamide (100mg/kg body weight) given subcutaneously. The rats were divided into 4 groups comprising of six animals in each group. These groups included a normal control and a cyclophosphamide induced thrombocytopenic control and the remaining two cyclophosphamide induced thrombocytopenic groups were administered Carica papaya leaf juice and hydrocortisone respectively.
\end{abstract}

The duration of study was 15 days. The clotting time was determined on the 15th day although blood samples were obtained from the rat tails at various time intervals to determine the platelet count.

Collected data was tabulated and Statistical analysis was performed by using appropriate significant test. A probability value $P<0.05$ was considered to be statistically significant.

\section{Result}

Average platelet counts of the test and control groups were $(6.89) \times 10^{5} / \mu \mathrm{L}$ and $(6.75) \times 10^{5} / \mu \mathrm{L}$ respectively before the experiment. In the experiment there was no significant difference in the platelet counts during the first 3 days in either group. However, platelet counts within the test group started to fall after Day 3 and remarkable thrombocytopenia developed after 7days and the average value was (2.68) $\times 10^{5} / \mu \mathrm{L}$. From day 11 Carica papaya leaf juice and Hydrocortisone was given in two test groups following cyclophosphamide and platelet counts observed to reach a peak level at Day 14 (7.83) $\times 10^{5} / \mu \mathrm{L}$ in case of following Carica papaya leaf juice, and (4.05) $\times 10^{5} / \mathrm{HL}$ in case of following Hydrocortisone. The clotting time was determined on day 15 and it was found to be considerably lower $(95.5 \pm 2.762 \mathrm{sec})$ in case of Carica papaya leaf juice than (129 $\pm 3.124 \mathrm{sec})$ in Hydrocortisone.

\section{Conclusion}

Carica papaya leaf juice has more platelet increasing effect than hydrocortisone and this study also reflects that Carica papaya leaf juice may be a potential candidate for further research leading to the development of a herbal therapeutic agent for thrombocytopenia manifested in diseases such as dengue.

Key words: Thrombocytopenia, Platelet, Carica papaya leaf juice, hydrocortisone, cyclophosphamide, dengue fever.

(Bangladesh J Physiol Pharmacol 2014;30(2):32-40) 


\section{INTRODUCTION}

Thrombocytopenia is a condition associated with the lower production of platelets than the normal numbers in the bone marrow and is often multifactorial. Diseases such as dengue, idiopathic thrombocytopenic purpura (ITP), malignancy, aplastic anemia, drug induced thrombocytopenic purpura (for example Heparin induced thrombocytopenia), hemolytic uremic syndrome etc. result in a low thrombocyte count in blood. ${ }^{1}$

The physiological range for thrombocytes in the normal healthy human is $150-400 \times 10^{9}$ per liter of blood. In rare cases, the number of platelets may be so low that dangerous internal bleeding can occur. ${ }^{2}$

The most common thrombocytopenic conditions found in Bangladesh are dengue fever, where thrombocytopenia is a result of platelet destruction, sequestration and importantly by bone marrow suppression. $^{3}$

The Dengue infection is the most rapidly spreading mosquito-borne viral disease in the world and an estimated 50 million dengue infections are reported annually ${ }^{4}$. The case fatality rates for the south-east Asian region are $1 \%$, but in India, Indonesia and Myanmar, focal outbreaks have reported rates of 3$5 \%{ }^{4}$

Thrombocytopenia is a constant manifestation in dengue fever, which often leads to life threatening Dengue Haemorrhagic Fever (DHF) and the Dengue Shock Syndrome (DSS). Both haemorrhagic diathesis and circulatory collapse are the fatal complications of the dengue infection. 5

Global attempts have been made to develop new treatment strategies to combat these fatal complications of the dengue infection. ${ }^{7}$ Steroids are used in the treatment of idiopathic thrombocytopenic purpura to increase the platelet count, which is mediated by auto antibodies. This practice supports the use of steroids in dengue fever. ${ }^{8}$.

There are limited studies in the literature which have assessed the benefits and the risk of the corticosteroid therapy in thrombocytopenia in the dengue infection. Various steroid regimens have been used and some of them have shown beneficial effects and some have shown no benefits. However, the Cochrane reviews have concluded that there is insufficient evidence on the use of steroids in DSS and DHF and they have advised large randomized trials. ${ }^{7}$ Kularathnesam et al. conducted a survey to take the opinions of physicians and pediatricians on the management of the dengue infection in Sri Lanka. It revealed that the World Health Organization (WHO) guidelines were followed by only

\footnotetext{
Address for correspondence: Dr. Tansena Akhter, Assistant Professor, Dept. of Pharmacology, Tairunnessa Memorial Medical College, Gazipur, Bangladesh. Phone: 01751354357, Email: tansena@yahoo.com
}

$16(45 \%)$ physicians and $6(40 \%)$ pediatricians in the management of DF and DHF and those steroids were used empirically in anticipation of bleeding diathesis. ${ }^{6}$ Rajapakshe et al. concluded in his study, that the possible effects of steroids on thrombocytopenia and bleeding in dengue fever were unknown, even though they were used empirically. ${ }^{9}$

All treatment options have their cons. Some cons include severe toxicities and immunosuppressant effects of corticosteroids, severe patient noncompliance in platelet transfusion. Nevertheless, due to certain side effects and the costs involved, the availability of treatment for thrombocytopenia is limited. Consideration should be given to alternate therapies to combat low platelet count. For example, herbal therapy is relatively free from the toxic side effects of the allopathic drugs, better patient tolerance, relatively less expensive and well accepted due to long history of use. $^{10}$ Recently, Carica papaya (family Caricaceae) leaves have been successfully employed in folk medicine for the treatment of dengue infections with haemorrhagic manifestations. ${ }^{11}$

Carica papaya is a large, tree-like plant with a single stem growing from 5 to $10 \mathrm{~m}$ [16 to $33 \mathrm{ft}$ ] tall, with spirally arranged leaves confined to the top of the trunk. The lower trunk is conspicuously scarred where leaves and fruit were borne. The leaves are large, 50-70 cm [20-28 inches] in diameter, deeply and palmately lobed with seven lobes. ${ }^{12} \mathrm{~A}$ lot of work has been carried out on plant parts like fruits, seeds and roots, indicating the presence of biologically active compounds. ${ }^{13}$

The qualitative test has already been carried out using Carica papaya leaves which gave results that Carica papaya leaves contain saponin, tannin, flavonoid, alkaloid and Glycoside. Chemical analysis of Carica.papaya leaves showed the presence of considerable amount of carpaine, malic acid, quinic acid, manghaslin and clitorin, minor quantities of various malic acid derivatives, nicotiflorin, rutin and unidentified constituents. ${ }^{14}$ These constituent can act on the bone marrow, prevent its destruction and enhance its ability to produce platelets. ${ }^{15}$

Cyclophosphamide is a synthetic alkylating agent used for its antineoplastic and immunosuppressive activities, and was introduced as an antitumour agent in 1958. Cyclophosphamide was used as toxicant in the current study because of its capacity to induce stable thrombocytopenia. ${ }^{16}$

In the current study, the competitive ability of Carica papaya leaf juice and hydrocortisone in increasing the platelet count in cyclophosphamide induced thrombocytopenic rats were evaluated. The clinical usage of Carica papaya leaves in dengue fever patient should be evaluated in large comparative trial. 


\section{MATERIALS AND METHODS}

\section{Experimental Animals}

From January 2013 to December 2013 an experimental study in animals (rats) carried out in the Department of Pharmacology of Dhaka Medical College, Dhaka.

The experiment was carried out on a total number of 24 healthy rats of Long Evans Norwegian strain weighing between 150-200 gm and age between 8-10 weeks. These rats were collected from Bangladesh Council of Scientific and Industrial Research (BCSIR) after proper authentication. They were kept in metallic cages ( 6 rats in each cage) in the animal house of department of pharmacology at Dhaka Medical College. The animals were allowed to live at room temperature, given standard rat foods and allowed to drink water. Proper cleaning measures were taken regularly.

\section{Preparation and Dosage of Carica papaya Leaf Juice}

Fresh, middle stage age, Carica papaya leaves were picked daily for 3 days. For the purpose of the study, a private plantation was identified to provide the leaves for the entire duration of the study. The plant was authenticated as Carica papaya by National Herbarium, Mirpur Dhaka. DACB. Accession number is 39501.

The trees in this plantation were kept free of herbicides, pesticides, and insecticides. Juice was prepared fresh from the leaves that were washed thoroughly. The veins and the petiole of the Carica papaya leaves selected for the tests was removed and Juice was extracted from fresh leaves using a juice extractor without any addition of water, under sterile conditions and the mucilaginous (with mucus) juice concentrate manually was separated (like squeezing coconut milk) from the leaf-residue. ${ }^{17}$

Then the mixture was filtered to obtain a pure extract of Carica papayaleaves. Finally, the volume of the extract was measured and the extracts were stored at $4^{\circ} \mathrm{C}$ until use and administered orally $2 \mathrm{ml} /$ day per rat. ${ }^{18}$

\section{Preparation and Dosage of Hydrocortisone}

$100 \mathrm{mg}$ Hydrocortisone vial was dissolved in $20 \mathrm{ml}$ distilled water and $0.1 \mathrm{ml}$ of that solution (containing $0.5 \mathrm{mg}$ Hydrocortisone) was given subcutaneously daily to each rat. ${ }^{19}$

\section{Establishment of Thrombocytopenia in the Rat Model}

Induction of thrombocytopenia was performed by the subcutaneous administration of freshly prepared Cyclophosphamide.

Each rat received $100 \mathrm{mg} / \mathrm{kg}$ body weight dose of Cyclophosphamide. It was dissolved with normal saline and administered by subcutaneous injection once a day for consecutive 3 days. Then it successfully initiated thrombocytopenia as the platelets number dropped at the 7 th day. ${ }^{16}$

\section{Experimental Procedure}

Experiment was comprised of 24 rats which were divided into 4 groups each having 6 rats. Groups were labeled as Group-A, Group-B, Group-C, and Group-D. It was carried out to demonstrate the effect of Carica papaya leaf juice in group $\mathrm{C}$ and Hydrocortisone in group $D$ in increasing platelet count following cyclophosphamide induced thrombocytopenia and compare the platelet increasing effect between group $\mathrm{C}$ and group D.

Group A (Control group): Rats $(n=6)$ received normal saline (10ml/kg p.o) for a period of 15 days. ${ }^{20}$

Group-B (Only Cyclophosphamide group): Rats $(n=6)$ received Cyclophosphamide $100 \mathrm{~g} / \mathrm{kg} \mathrm{s} / \mathrm{c}$ for $1^{\text {st }}$ 3 days ${ }^{16}$ and after that they received normal saline up to 15 days. $^{20}$

Group-C (Group for Papaya leaf juice): Rats $(n=6)$ received Cyclophosphamide $100 \mathrm{~g} / \mathrm{kg} \mathrm{s} / \mathrm{c}$ for $1^{\text {st }} 3$ days and since day 4 they received normal saline $(10 \mathrm{ml} / \mathrm{kg}$ p.o) up to day 10 and observed for development of thrombocytopenia. From day 11 they received Papaya leaf juice $2 \mathrm{ml} /$ day orally through ryles tube for next 3days. ${ }^{16,18}$

Group-D (Group for Hydrocortisone): Rats $(n=6)$ received Cyclophosphamide $100 \mathrm{mg} / \mathrm{kg} \mathrm{s} / \mathrm{c}$ for $1^{\text {st }} 3$ days and since day 4 they received normal saline $(10 \mathrm{ml} / \mathrm{kg}$ p.o) up to day 10 and observed for development of thrombocytopenia and from day 11 they received inj. hydrocortisone $0.5 \mathrm{mg}$ per day s/c for 3days. ${ }^{16,19}$

\section{Blood collection}

Blood was collected from each of the rats by aseptically cutting the tail at the tip with a sharp sterile blade on the $1^{\text {st }}, 4^{\text {th }}, 11^{\text {th }}$ and $14^{\text {th }}$ day of study. On the 15 th day, the clotting time of blood was determined by capillary method. ${ }^{20}$

\section{Platelet Examination}

Induction of thrombocytopenia was established by determining platelet counts with the use of Neubauer's improved Haemocytometer according to standard protocols. Briefly, blood obtained from the tail bleed of rats was added to EDTA containing tubes. Twenty microliters of blood was mixed thoroughly with $0.38 \mathrm{ml}$ of diluting fluid ( $1 \%$ ammonium oxalate freshly prepared) for at least 10 minutes. The haemocytometer filled with this mixture was incubated in a moist chamber for 10-20 minutes to allow the platelets to settle down. Round to oval shaped platelets were counted in the triple laminated middle 25 squares of the haemocytometer, using oil immersion light microscopy. ${ }^{21}$ 
Comparative Evaluation of Platelet Augmentation Activity of Carica Papaya Leaf Juice And Hydrocortisone In Thrombocytopenic RATs

\section{Data Collection}

Data were collected in predesigned data collection sheet and data were sorted for analysis.

\section{Statistical Analysis}

Statistical analysis was done by Microsoft Excel 2007 Data Analysis Module. Student's paired and unpaired ' $t$ ' test was used to compare the results. The results were presented in Mean $( \pm S D)$. Level of significance was < 0.05 .

\section{RESULTS}

Average platelet counts of the test and control groups were $(6.89) \times 10^{5} / \mu \mathrm{L}$ and $(6.75) \times 10^{5} / \mu \mathrm{L}$ respectively before the experiment. In the experiment there was no significant difference in the platelet counts during the first 3 days in either group. However, platelet counts within the test group started to fall after Day 3 and remarkable thrombocytopenia developed after 7days and the average value was $(2.68) \times 10^{5} / \mu \mathrm{L}$. From day 11 Carica papaya leaf juice and Hydrocortisone was given in two test group following cyclophosphamide respectively and platelet counts observed to reach a peak level at Day $14(7.83) \times 10^{5} / \mu \mathrm{L}$ in case of following Carica papaya leaf juice, and $(4.05) \times 10^{5} / \mu \mathrm{L}$ in case of following Hydrocortisone. The clotting time was determined on day 15 and it was found to be considerably lower $(95.5 \pm 2.762 \mathrm{sec})$ in case of Carica papaya leaf juice than $(129 \pm 3.124 \mathrm{sec})$ in Hydrocortisone.

Table - I

Day wise platelet count $/ \mu L$ (Mean \pm SD) for Experiment

\begin{tabular}{|r|c|c|c|c|}
\hline Day & $\begin{array}{c}\text { platelet count (per } \\
\mu \mathrm{L} \text { ) (Mean } \pm \text { SD) } \\
\text { Group A }\end{array}$ & $\begin{array}{c}\text { platelet count (per } \\
\mu \mathrm{L} \text { ) (Mean } \pm \text { SD) } \\
\text { Group B }\end{array}$ & $\begin{array}{c}\text { platelet count (per } \\
\mu \mathrm{L} \text { ) (Mean } \pm \text { SD) } \\
\text { Group C }\end{array}$ & $\begin{array}{c}\text { platelet count (per } \\
\mu \mathrm{L} \text { ) (Mean } \pm \text { SD) } \\
\text { Group D }\end{array}$ \\
\hline $\mathbf{1}$ & $696,667 \pm 68,020$ & $756,667 \pm 68,020$ & $697,500 \pm 65,403$ & $713,333 \pm 82,865$ \\
\hline $\mathbf{4}$ & $686,667 \pm 61,097$ & $656,667 \pm 62,065$ & $600,000 \pm 59,457$ & $610,000 \pm 69,967$ \\
\hline $\mathbf{1 1}$ & $706,667 \pm 68,896$ & $68,333 \pm 10,328$ & $218,333 \pm 27,869$ & $221,667 \pm 51,543$ \\
\hline $\mathbf{1 4}$ & $689,167 \pm 60,243$ & $164,167 \pm 8,612$ & $783,333 \pm 44,572$ & $405,000 \pm 38,859$ \\
\hline
\end{tabular}

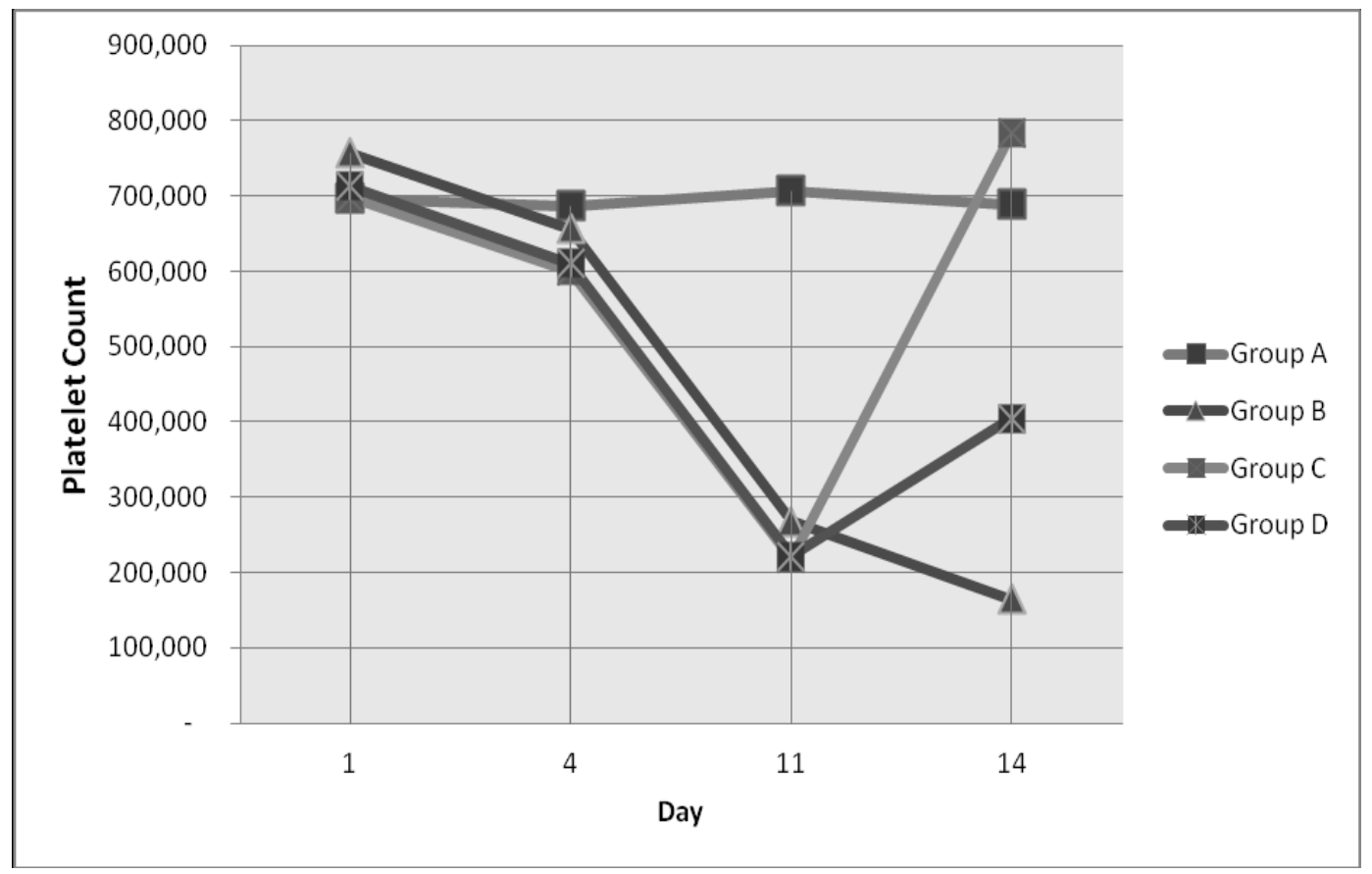

Figure 1: Line Graph for day wise platelet count (per $\mu \mathrm{L}$ ) 


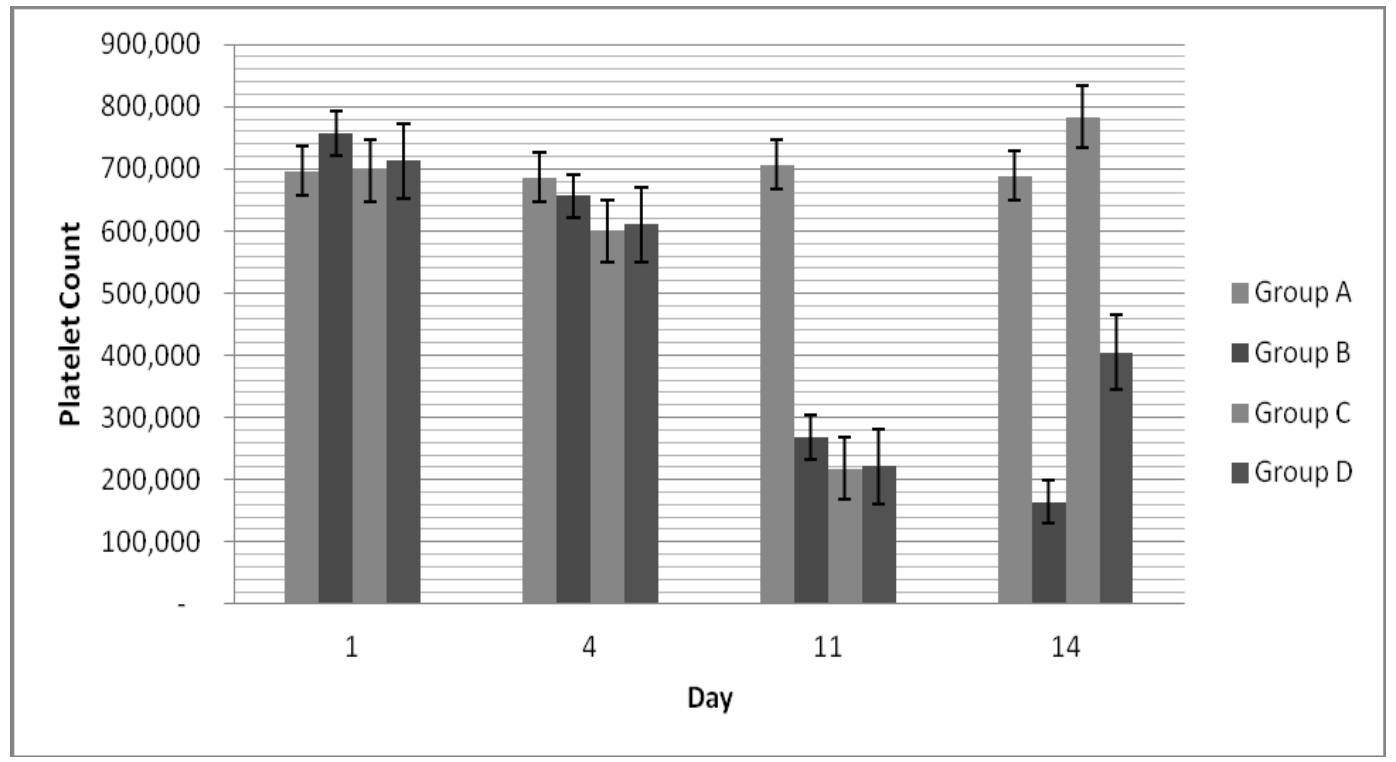

Figure 2: Bar Graph for Day wise platelet count (per $\mu \mathrm{L})($ Mean $\pm \mathrm{SD}$ )

* Vertical bar in the diagram indicates standard deviation.

To Find out the Effect of Carica papaya Leaf Juice on Platelet Count

Unpaired and paired student's 't'-test was done between group A, B, and C on day 1,11 and 14 and $p$-value $<0.05$ is significant.

Table - II

Platelet count (Mean $\pm S D$ ) / $\mu$ l of Group $A, B, C$ in day 1

\begin{tabular}{|c|c|c|c|l|}
\hline Day-1 & Group A & Group B & Group C & \multicolumn{1}{|c|}{ P-value } \\
\hline \multirow{2}{*}{$\begin{array}{l}\text { Platelet Count } \\
\text { (Mean } \pm \text { SD) } / \boldsymbol{\mu L}\end{array}$} & $696,667 \pm 68,020$ & $756,667 \pm 68,020$ & ----- & 0.157 \\
\cline { 2 - 5 } & $696,667 \pm 68,020$ & ------ & $697,500 \pm 65,403$ & 0.983 \\
\hline
\end{tabular}

Unpaired student's 't'-test done between A \& B and A \& C on day-1 and p-value >0.05, the result is not significant.

Table - III

Platelet count (Mean $\pm S D$ ) $/ \mu$ l of Group A, B, C in day 11

\begin{tabular}{|c|l|c|l|l|}
\hline Day-11 & \multicolumn{1}{|c|}{ Group A } & Group B & \multicolumn{1}{c|}{ Group C } & \multicolumn{1}{c|}{ P-value } \\
\hline $\begin{array}{l}\text { Platelet Count } \\
\text { (Mean } \pm \text { SD) } / \boldsymbol{\mu L}\end{array}$ & $706,667 \pm 68,896$ & $268,333 \pm 10,328$ & ----- & $0.00002 * *$ \\
\cline { 2 - 5 } & ------ & $268,333 \pm 10,328$ & $218,333 \pm 27,869$ & 0.084 \\
\hline
\end{tabular}

Unpaired student's 't'-test done between A \& B and B \&C on day-11 


\section{Table - IV}

Platelet count (Mean $\pm S D$ ) $/ \mu$ of Group $B, C$ in day 14

\begin{tabular}{|c|c|c|c|}
\hline Day-11 & Group B & Group C & p-value \\
\hline $\begin{array}{l}\text { Platelet Count } \\
(\text { Mean } \mathbf{S D} \text { ) } / \boldsymbol{\mu L}\end{array}$ & $164,167 \pm 8,612$ & $783,333 \pm 44,572$ & $0.0000004 * *$ \\
\hline
\end{tabular}

Unpaired t-test between $B$ \& $C$ on day-14 and p-value $<0.05$, the result is significant.

Table - V

Platelet count (Mean $\pm S D$ ) / $\mu$ l of Group $C$ in day 11 and day 14

\begin{tabular}{|c|c|c|c|}
\hline Group C & Day-11 & Day-14 & p-value \\
\hline $\begin{array}{l}\text { Platelet Count } \\
\text { (Mean } \pm \text { SD) } / \boldsymbol{\mu L}\end{array}$ & $221,666 \pm 27868$ & $783,333 \pm 44572$ & $0.00000003 * *$ \\
\hline
\end{tabular}

Paired t-test between Group C on day-11 and Group C on day-14 and p-value $<0.05$, the result is significant. It can be concluded that Carica papaya leaf juice has platelet increasing effect on thrombocytopenic rats.

\section{To Find out the Effect of Hydrocortisone on Platelet Count}

Unpaired and paired student's 't'-test was done between group A, C, and D on day 1,11 and 14 and $p$-value $<0.05$ is significant.

Table - VI

Platelet count (Mean $\pm S D$ ) / $\mu$ l of Group $A, C$, D in day 1

\begin{tabular}{|c|c|c|c|l|}
\hline Day-1 & Group A & Group C & Group D & P-value \\
\hline \multirow{2}{*}{$\begin{array}{l}\text { Platelet Count } \\
\text { (Mean } \pm \text { SD)/ } \boldsymbol{\mu L}\end{array}$} & $696,667 \pm 68,020$ & $697,500 \pm 65,403$ & ------ & 0.983 \\
\cline { 2 - 5 } & $696,667 \pm 68,020$ & ------ & $713,333 \pm 82,865$ & 0.711 \\
\hline
\end{tabular}

Unpaired student's 't'-test done between A \& C and A \&D on day-1

Table - VII

Platelet count (Mean $\pm S D$ ) $/ \mu$ of Group $A, C$, D in day 11

\begin{tabular}{|c|c|c|c|c|}
\hline Day-11 & Group A & Group C & Group D & P-value \\
\hline \multirow{2}{*}{$\begin{array}{l}\text { Platelet Count } \\
(\text { Mean } \pm S D) / \mu L\end{array}$} & $706,667 \pm 68,896$ & ------- & $221,667 \pm 51,543$ & $0.00000023 * *$ \\
\hline & ------- & $218,333 \pm 27,869$ & $221,667 \pm 51,543$ & 1.00 \\
\hline
\end{tabular}

Unpaired t-test between A \& D and C \& D on day-11.

Table - VIII

Platelet count (Mean $\pm S D$ ) / $\mu$ l of Group D on day 11 and day 14

\begin{tabular}{|l|l|l|c|}
\hline Group D & Day-11 & Day-14 & p-value \\
\hline $\begin{array}{l}\text { Platelet Count } \\
\text { (Mean } \pm \text { SD) } / \boldsymbol{\mu L}\end{array}$ & $221,667 \pm 51,543$ & $405,000 \pm 44,572$ & $0.0000272 * *$ \\
\hline
\end{tabular}

Paired t-test between Group D on day-11 and Group D on day-14 and p-value $<0.05$, the result is significant. It can be concluded that hydrocortisone has platelet increasing effect on thrombocytopenic rats.

Comparison of Carica papaya Leaf Juice with Hydrocortisone on Platelet count 
Unpaired student's 't'-test done between group $C$, and D on day 14 and p-value $<0.05$ is significant.

Table - IX

Platelet count (Mean $\pm S D$ ) / $/ \mu$ of Group C, D in day 14

\begin{tabular}{|l|l|l|c|}
\hline Day-14 & Group C & Group D & p-value \\
\hline $\begin{array}{l}\text { Platelet Count } \\
\text { (Mean } \pm \text { SD) } / \mu \mathrm{L}\end{array}$ & $783,333 \pm 44,572$ & $405,000 \pm 44,572$ & $0.00000002 * *$ \\
\hline
\end{tabular}

Unpaired t-test between C \& D on day-14 and P-value $<0.05$, the result is significant.

It can be concluded that Carica papaya leaf juice has higher platelet increasing effect than Hydrocortisone on thrombocytopenic rats.

Effect of Carica papaya Leaf Juice and Hydrocortisone on Clotting Time in Rats

Table $-\mathbf{x}$

Clotting time (sec.) on day 15

\begin{tabular}{|l|l|l|l|l|}
\hline & \multicolumn{4}{|l|}{ Mean clotting time (sec.) on day 15 } \\
\hline Groups & $\begin{array}{l}\text { Normal } \\
\text { Control (A) }\end{array}$ & $\begin{array}{l}\text { Cyclophosphamide } \\
\text { control (B) } \\
(100 \mathrm{mg} / \mathrm{kg})\end{array}$ & $\begin{array}{l}\text { Carica papaya } \\
\text { leaf juice (C) } \\
\text { 2ml/per rat }\end{array}$ & $\begin{array}{l}\text { Hydrocortisone } \\
\text { (D) (0.5mg/per } \\
\text { rat) }\end{array}$ \\
\hline Time (in ecs) & $98.5 \pm 2.625$ & $160 \pm 5.025$ & $95.5 \pm 2.762$ & $129 \pm 3.124$ \\
\hline
\end{tabular}

The clotting time of group $C$ was found to be considerably lower than group $D$.

* Relation between platelet counts and clotting time inversely proportional.

\section{DISCUSSION}

The Dengue infection results in significant morbidity and mortality worldwide. The current recommended treatment is largely supportive, with careful fluid replacement and with no specific treatment being available at present. $^{6}$ The common goal in treating these patients with severe thrombocytopenia is to stabilize the platelet count, which will prevent the major risk of bleeding. ${ }^{22}$ Corticosteroids are potent antiinflammatory agents that have a wide range of effects on the immunological processes. Although corticosteroids are not mentioned in the WHO guidelines on the management of dengue, clinicians use corticosteroids empirically, based on the presumed immunological basis of the complications of dengue, particularly in the South East Asian countries. ${ }^{6}$

Shashidhara et al., (2013) conducted an experiment to evaluate the Effect of High Dose of Steroid on Platelet count in Acute Stage of Dengue Fever with Thrombocytopenia and concluded that at a high dose dexamethasone regimen was not effective in achieving a higher rise in the platelet count in the acute stage of dengue fever. ${ }^{23}$

The study of Rajapakse et al., (2014) showed that there is currently no high quality evidence supporting the beneficial effects of corticosteroids for treatment of shock, prevention of serious complications or increasing platelet counts. ${ }^{24}$

Panpanich et al., (2006) observed an increased mortality after the use of steroids in DSS and DHF and gave opinion that it was difficult to conduct a study on life threatening illnesses like DSS and DHF, as steroids would have compounding effects on the outcome of the disease. $^{7}$

In view of these observations, the empirical use of steroids may be avoided in dengue fever with thrombocytopenia. Therefore in our study we compare the platelet increasing effect of Carica papaya leaf juice and hydrocortisone in experimental rats.

The increase in the blood count by Carica papaya leaves is well established in several regions including Australia, South America, Philippines and Africa, and has shown proven results of drastic boosts in platelet count. ${ }^{25}$

Hettige (2008) has shown that Carica papaya leaves contain complex substances that may support the release and production of platelets by the bone marrow and helps to normalize clotting and repair liver damage caused by dengue. ${ }^{26}$

Patil et al., (2013) performed a study to evaluate the effect of Carica papaya leaves aqueous extract in increasing the platelet count in thrombocytopenic rats 
aimed to determine the possible effects of papaya leaves in thrombocytopenia occurring in dengue fever. ${ }^{20}$

Tham et al., (2013) tested antioxidant and haemopoietic properties of leaves of Carica papaya against the effect of lead acetate in experimental rats and concluded that Carica papayawas effective against the oxidative damage caused by lead acetate in the bone marrow and had a stimulatory effect on haemopoiesis. ${ }^{27}$

Gammulle et al., (2012) conducted a study in rats and showed freshly prepared mature leaf concentrate of Carica papaya effectively increases rat platelet, WBC and RBC counts with no acute toxicity, and possesses potent anti-inflammatory activity. ${ }^{28}$

Dharmarathnaa et al., (2013) investigated the potential role of fresh Carica papaya leaf extract on haematological and biochemical parameters and toxicological changes in a murine model and recommended to use as a medication to boost thrombopoiesis and erythropoiesis in humans and in animals in which these cell lineages have been compromised. ${ }^{14}$

Subenthiran et al., (2013) conducted a study to investigate the platelet increasing property of Carica papaya leaves juice in patients with dengue fever and showed that there was a 15 -fold increase in the ALOX 12 gene activity among the patients in the experimental group as compared to those in the control group at the end of the 3 days. ALOX 12 gene is known to be associated with increased megakaryocyte production as well as its conversion to platelets through 12-HETE mediated pathway which in turn leads to increased platelet production. ${ }^{17}$

The present study, for the first time, evaluates the comparative increasing platelet effect of freshly prepared leaf concentrate of Carica papaya and hydrocortisone in induced thrombocytopenic rats. This was an important therapeutic investigation as there is no effective treatment method for thrombocytopenia at present.

Importantly, this study, established a rat model for thrombocytopenia by using Cyclophosphamide. As this drug is claimed to be highly toxic, a low dose of cyclophosphamide was used to induce stable thrombocytopenia in rats. The dose, duration and route of administration of cyclophosphamide was selected from Patil et al. and Hong et al. respectively. ${ }^{20,16}$ In this study, subcutaneous (s/c) administration of cyclophosphamide $(100 \mathrm{mg} / \mathrm{kg})$ was given daily for 3 consecutive days which decreased platelet count significantly in experiment at the 7th day and all groups were under investigation for 15 days. ${ }^{16,20}$ Similar observations were reported by Hong et al. and Patil et al. The dose of Carica papaya leaf juice was 2000 $\mathrm{mg} / \mathrm{kg}$ body weight ( $2 \mathrm{ml}$ in volume per $200 \mathrm{gm}$ weighted rat) and it was given orally once for 3 days. The dose used in this study was selected in conformance with the dose used in research work by Halim et al., 2011. ${ }^{18}$

The dose of hydrocortisone $0.5 \mathrm{mg} /$ day per rat for 3 days, used in this study was selected in conformance with the dose used in research work by Rinehart et al., 1997. ${ }^{19}$

The platelet counts in animals were measured in different time interval and measuring procedure followed according to experiment of other researchers. ${ }^{20,21}$

In present study, the clotting time was determined on the 15th day of the study by capillary method. Carica papayaleaf juice was found to increase the platelet count and also to decrease the clotting time in rats.

Thus, the findings of this study are in well agreement with the findings of Patil et al., (2013) and Shashidhara et al., (2013)..$^{20,23}$

Increment in the mean value of platelet count was observed in the experimental thrombocytopenic group when treated with Carica papaya leaf juice at a dose of $2 \mathrm{ml} /$ per day per rat and hydrocortisone at a dose of 0.5 $\mathrm{mg} /$ day per rat and these changes were significant.

The findings of the present study strongly suggests that Carica papaya leaf juice has more platelet increasing effect than hydrocortisone and there could be some active compounds in Carica papayaleaves that can enhance haemopoiesis and thrombopoiesis in animals.

For future study, it is suggested to measure RBC, WBC, PCV, SGPT, SGOT, and Serum Creatinine after treatment with Carica papaya leaf juice.

\section{CONCLUSION}

Carica papaya leaf juice has more platelet increasing effect than hydrocortisone and this study also reflects that Carica papaya leaf juice may be a potential candidate for further research leading to the development of a herbal therapeutic agent for thrombocytopenia manifested in diseases such as dengue. However, this is a preliminary study and more work is needed to isolate and identify the biologically active ingredients of Carica papaya leaves to create a suitable formula responsible for the release and/or production of the thrombocytes (platelets).

\section{REFERENCES}

1. Aster $\mathrm{RH}$, Bougie DW. Drug-induced thrombocytopenia. New England J Med 2007; 357: 580-87.

2. Wong W, Glader B. Approach to the Newborn Who Has Thrombocytopenia. Neo Reviews 2004: 5.

3. http://WWW.dhakatribune.com/safety/2013/sep/03/denguerise-dengue [accessed November 2014] 
4. WHO. Dengue Guideline for diagnosis, treatment, prevention and control. Geneva: World Health Organization 2009.

5. Messer WB, Vitarana UT, Sivananthan K, Elvtigala J, Preethimala LD, Ramesh R, Withana N, Gubler DJ, De Silva AM. Epidemiology of dengue in Sri Lanka before and after the emergence of epidemic dengue hemorrhagic fever. Am J Trop Med Hyg 2002; 66: 765-73.

6. Kularatne SAM. Survey on the management of dengue infection in Sri Lanka: Opinion of physicians and pediatricians. Southeast Asian J Trop Med Pub Health 2005; 36: 1198-200.

7. Panpanich R, Sornchai P, Kanjanaratanakorn K. Corticosteroids for treating dengueshock syndrome. Cochrane Database of Systematic. Reviews 2006; (issue 3):CD003488.

8. Cines DB, Blanchette VS. Immune thrombocytopenic purpura. N Engl J Med 2002; 346: 995-1008.

9. Rajapakse S. Corticosteroids in the treatment of dengue illness. Trans R Soc Trop Med Hyg 2009; 103: 122-26.

10. Mayo Foundation for Medical Education and Research. Prednisone and other corticosteroids: Balance the risks and benefits 2006.2 [online]. http://www.mayoclinic.com/health/steroids/HQ01431. (accessed September 2007).

11. Sathasivam K, Ramanathan S, Mansor S, Haris M, Wernsdorfer W. Thrombocyte count in mice after administration of Carica papaya leaf suspension. The Middle European Journal of Medicine 2009; 121: 19-22

12. Hasheen FM. Antibacterial activity of Carica papaya Extract. Oxford University press, New York. 2007; pp. 15-25.

13. Otsuki N, Dang $\mathrm{NH}$, Kumagai $\mathrm{E}$, Kondo $\mathrm{A}$, Iwata $\mathrm{S}$, Morimoto C. Aqueous extract of Carica papaya leaves exhibits anti-tumor activity and immunomodulatory effects. J Ethnopharmacol 2010; 127: 760-67.

14. Dharmarathna ACLS, Wickramasinghe $\mathrm{S}$, Waduge $\mathrm{N} \quad \mathrm{R}$ Rajapakse JVPR, Kularatne MAS. Does Carica papaya leafextract increase the platelet count? An experimental study in a murine model. Asian Pacific Journal of Tropical Biomedicine 2013; 3: 720-724.

15. Yunita F, Hanani E, Kristianto J. The effect of Carica papaya leaves extract capsules on platelets count and hematocrit leve in dengue fever patient. Int. J. Med. Arom. Plants 2012; 2: 573578.

16. Hong N, Kong-yan L, Xiao-qi Z, Xue-ying F, Duan-rong Y, Yu-si W, Jiu-yao Z, Wen-cai Y. Establishment of a Mouse Thrombocytopenia Model Induced by Cyclophosphamide. Zoological research 2009; 30: 645-52.

17. Subenthiran S, Choon CT, Cheong CK, Thayan R, Teck BM, Muniandy $\mathrm{KP}$, et al. Carica papaya Leaves Juice Significantly Accelerates the Rate of Increase in Platelet Count among Patients with Dengue Fever and Dengue Haemorrhagic Fever 2013.

18. Halim ZS, Abdullah RN, Afzanl A, Abdul Rashid AB, Jantan I Ismail Z. Acute toxicity study of Carica papaya leaf extract in Sprague Dawley rats Journal of Medicinal Plants Research 2011; 5:1867-1872.

19. Rinehart J, Keville L, Clayton S, Figueroa JA. Corticosteroids alter hematopoiesis in vitro by enhancing human monocyte secretion of granulocyte colony-stimulating factor. Exp Hematol 1997; 25(5):405-12

20. Patil S, Shetty S, Bhide R, Narayanan S. Evaluation of platelet augmentation activity of Carica papaya leaf aqueous extract in rats. Journal of Pharmacognosy and phytochemistry 2013; 1(5):59-61.

21. Brecker G, Cronkite E. Morphology and enumeration of human blood platelets. J Applications Physiol 1950; 3: 365-371
22. Gupta $E$, Dar L, Narang $P$, Srivastava VK, Broor S. Sero diagnosis of dengue during an outbreak at a tertiary care hospital in Delhi. Indian J Med Res 2005; 121:36-38.

23. Shashidhara C K, Murthy S A K, Gowdappa B H, Bhograj A. Effect of High Dose of Steroid on Plateletcount in Acute Stage of Dengue Fever with Thrombocytopenia. JCDR Research \& Publications Private Limited 2013; 7(7):1397-1400

24. Rajapakse S, Rodrigo C, Maduranga S, Rajapakse CA Corticosteroids in the treatment of dengue shock syndrome. Dove Press Journal:Infection and Drug Resistance 2014; 7:137143

25. Zunjar V, Mammed D, Trivedi BM, Daniel M. Pharmacognostic, physiochemical and phytochemical studies on Carica papaya Linn leaves. Pharmacognosy Journal 2011; (3):5-8.

26. Hettige S. Salutary effects of Carica papaya leaf extract in dengue fever patients- a pilot study. Sri Lankan Family Physician 2008; 29: 17-19

27. Tham SC, Chakravarthi S, Haleagrahara N, Alwis DR Morphological study of bone marrow to assess the effects of lead acetate on haemopoiesis and aplasia and the ameliorating role of Carica papaya extract . Exp Ther Med 2013; 5(2): 648652.

28. Gammulle A, Ratnasooriya DW, Jayakody CARJ, Fernando C, Kanatiwela C, Udagama VP. Thrombocytosis and Antiinflammatory Properties and Toxicological Evaluation of Carica papaya Mature Leaf Concentrate in a Murine Model. Online Int J Medicinal Plants Res 2012; 1(2):21-30. 